\title{
Making People's Life Most Worth Living: On the Importance of Passion for Positive Psychology
}

\author{
Haciendo que la vida de la gente merezca ser plenamente vivida: \\ La importancia de la pasión para la Psicología Positiva
}

\author{
Robert J. Vallerand \\ Jérémie Verner-Filion \\ Laboratoire de Recherche sur le Comportement Social \\ Université du Québec à Montréal, Canada
}

(Rec:05 de enero de 2013 / Acep: 14 de enero de 2013 )

\begin{abstract}
The purpose of the present paper is to present the Dualistic Model of Passion (Vallerand et al., 2003) and show its importance for positive psychology. Passion is defined as a strong inclination toward a self-defining activity that people like (or love), find important, and in which they invest time and energy. Furthermore, two types of passion (harmonious and obsessive) are proposed. Harmonious passion leads people to choose to engage in the activity that they love. Conversely, obsessive passion creates an internal pressure to engage in the beloved activity. Harmonious passion is hypothesized to lead to more adaptive outcomes than obsessive passion. Results of several studies reveal that passion matters with respect to a number of outcomes deemed important for positive psychology such as flow and positive emotions, psychological well-being, physical health, relationships, and performance. Passion can indeed make people's lives worth living to the extent that it is harmonious in nature.
\end{abstract}

Key words : passion, self-determination theory, performance, well-being

\section{Resumen}

El objetivo del presente trabajo es presentar el Modelo Dualista de la Pasión (Vallerand et al., 2003) y mostrar su importancia para la psicología positiva. La pasión se define como una fuerte inclinación hacia una actividad que a la gente le gusta (o ama), le parece importante, y en la que invierte tiempo y energía. El modelo plantea la existencia de dos tipos de pasión (armoniosa y obsesiva). La pasión armoniosa conduce a la gente a elegir dedicarse a la actividad que aman. Por el contrario, la pasión obsesiva crea una presión interna para dedicarse a la actividad deseada. Se hipotetiza que la pasión armoniosa conduce a resultados más adaptativos que la pasión obsesiva. Los resultados de diferentes estudios revelan que la pasión es importante en relación a una serie de resultados que se consideran importantes para la Psicología positiva tales como el fluir (flow) y las emociones positivas, el bienestar psicológico, la salud física, las relaciones, y el rendimiento. La pasión realmente puede hacer que la gente tenga vidas que merezcan la pena en la medida en que dicha pasión sea de naturaleza armónica.

Palabras clave: pasión, teoría de la auto-determinación, rendimiento, bienestar.

Correspondence: Robert J. Vallerand, Ph.D, Laboratoire de Recherche sur le, Comportement Social, Département de Psychologie, Université du Québec à Montréal, P. O. Box. 8888, Station «Ctr-ville», Montreal (Quebec), Canada H3C 3P8, Tel: (514) 987-4836, Fax: (514) 987-7953. e-mail: vallerand. robert_J@uqam.ca 


\section{Introduction}

Positive psychology refers to the scientific study (and scientifically informed applications) of the factors that allow individuals (and organizations and communities) to thrive and feel like life is worth living for. Several factors have been found to make one's life worth living for (see Peterson, 2006 for a review). It is proposed that passion represents another important factor to consider within such a perspective. Indeed, regularly feeling excited and enthusiastic as one engages in an enjoyable and meaningful activity should affect people's life in a positive and significant way. In fact, research on passion does reveal that passion can positively affect a number of outcomes deemed important in positive psychology such as flow and positive emotions, psychological well-being, physical health, relationships, and performance (Vallerand, 2010). However, research reveals that passion can also negatively affect the same outcomes (Vallerand, 2010). Because these various outcomes have been hailed as highly meaningful in positive psychology, the study of passion becomes important in order to determine how it can best be harnessed to make life most worth living.

The goal of this article is to present the Dualistic Model of Passion (Vallerand et al., 2003; Vallerand, 2010) and show how passion can influence a number of outcomes found important in positive psychology. We start with a brief history of the concept of passion and then present the Dualistic Model of Passion. Subsequently, we review research on the role of passion in a number of outcomes important for positive psychology: flow and positive emotions, psychological well-being, physical health, relationships, and performance.

\section{A Brief History on Passion}

Relatively little research has focused on the psychology of passion. However, passion has generated a lot of attention from philosophers. Two distinct perspectives have emerged (Rony, 1990). The first posits that passion entails a loss of reason and control. For instance, for Plato (429-347 BC), reason moves people upward toward the divine, whereas passions bring people downward toward animal instincts and the flesh. Similarly, Spinoza (1632-1677) proposed that acceptable thoughts originated from reason, whereas unacceptable thoughts derived from passion. People afflicted with passion were seen as experiencing a kind of suffering, in line with the etymology of the word passion (from the latin "passio" for suffering). According to this perspective, individuals with a passion are seen as passive, as slaves to their passion, because it comes to control them.

The second perspective portrays passions in a more positive light. For instance, Aristotle proposed that people should not be ashamed of their passions as they reflect human qualities, or what it is to be human. However, Aristotle nevertheless recommended that passions be controlled by reason in order to prevent negative outcomes from taking place. Similarly, in "The Passions of the Soul" (1649/1972), Descartes (1596-1650) defined passions as strong emotions with inherent behavioral tendencies that could be positive as long as reason underlies the behavior. Rousseau (1712-1778) went further and even suggested that passion could lead to knowledge and truth. Hegel (1770-1831) further argued that passions were highly energetic and, in fact, necessary to reach the highest levels of achievement. Others, like Kierkegaard (1813-1855) even suggested that: "To exist, if we do not mean by that only a pseudo existence, cannot take place without passion". Thus, this second view of passion not only sees people as more active in relation to their passion, but also suggests that adaptive benefits will accrue when individuals are in control of their passion.

Very little has been written on the psychology of passion. The few psychologists who have looked at the concept have underscored its motivational aspect. For instance, Frijda, Mesquita, Sonemans, \& Van Goozen (1991) posited that "Passions are defined as high-priority goals with emotionally important outcomes" (p. 218). According to these authors, individuals spend large amounts of time and effort in order to reach their passionate goals. Other researchers have proposed that passion (or love) for work as an entrepreneur plays a major role in how one's vision is accepted in the organization and the performance of the company (Baum \& Locke, 2004). Most empirical work on passion has been conducted in the area of close relationships under the rubric of passionate love (e.g., Hatfield \& Walster, 1978; Sternberg, 1986). Although such research is important, it does not deal with the main topic at hand, namely passion toward activities.

\section{A Dualistic Model of Passion}

In line with Self-Determination Theory (SDT; Deci \& Ryan, 2000), we propose that people engage in various activities throughout life in the hope of satisfying the basic psychological needs of autonomy (to feel a sense of personal initiative), competence (to interact effectively with 
the environment), and relatedness (to feel connected to significant others). With time and experience, most people eventually start to display preference for some activities, especially those that are enjoyable and allow the satisfaction of the aforementioned basic psychological needs. Of these activities, a limited few will be perceived as particularly enjoyable and important, and to have some resonance with our identity or how we see ourselves. These activities become passionate activities. In line with the above, passion is defined as a strong inclination toward a self-defining activity that one likes (or even loves), finds important, and in which one invests time and energy (Vallerand et al., 2003). These activities come to be so self-defining that they represent central features of one's identity. For instance, those who have a passion for playing basketball or playing the guitar do not merely engage in these activities. They see themselves as "basketball players" and "guitar players". This will be the case to the extent that the activity is highly valued by the person (Aron, Aron, \& Smollan, 1992), thereby leading to a passion toward that activity.

Past research has shown that values and regulations concerning non-interesting activities can be internalized in either a controlled or an autonomous fashion (see Deci et al., 1994; Sheldon, 2002; Vallerand, 2001, 2007; Vallerand, Fortier, \& Guay, 1997). Similarly, it is posited that activities that people like will also be internalized in the person's identity to the extent that these are highly valued and meaningful for the person. Furthermore, it is proposed that there are two types of passion, harmonious and obsessive, that can be distinguished in terms of how the passionate activity has been internalized into one's identity. Harmonious passion results from an autonomous internalization of the activity into the person's identity and self. An autonomous internalization occurs when individuals have freely accepted the activity as important for them without any contingencies attached to it. This type of internalization emanates from the intrinsic and integrative tendencies of the self (Deci \& Ryan, 2000; Ryan \& Deci, 2003) and produces a motivational force to willingly engage in the activity that one loves and engenders a sense of volition and personal endorsement about pursuing the activity. When harmonious passion is at play, individuals do not experience an uncontrollable urge to engage in the passionate activity, but rather freely choose to do so. With this type of passion, the activity occupies a significant but not overpowering space in the person's identity and is in harmony with other aspects of the person's life. In other words, with harmonious passion the authentic integrating self (Deci \& Ryan, 2000) is at play allowing the person to fully partake in the passionate activity in a mindful (Brown \& Ryan, 2003) and open way (Hodgins \& Knee, 2002) that is conducive to positive experiences.

In line with the above, engaging in an activity with a harmonious passion should allow people to fully focus on the task at hand and to experience positive outcomes both during task engagement (e.g., positive affect, concentration, flow etc.) and after task engagement (general positive affect, life satisfaction etc.). Thus, there should be little or no conflict between the person's passionate activity and his/her other life activities. Furthermore, when prevented from engaging in their passionate activity, people with a harmonious passion should be able to adapt well to the situation and focus their attention and energy on other tasks that need to be done. Finally, with harmonious passion, the person is in control of the activity and can decide when to and when not to engage in the activity. For instance, a university student with a harmonious passion for basketball should be able to resist playing basketball with his friends the night before presenting an important oral presentation that still needs work. Thus, when confronted with the possibility of playing basketball with his friends or preparing tomorrow's presentation, the student with a harmonious passion can readily tell his friends that he'll take a rain check and proceed to be fully immersed in the preparation of the presentation without thinking about basketball. People with a harmonious passion are able to decide not to play on a given day if needed or even to eventually terminate the relationship with the activity if they decide it has become a permanent negative factor in their life. Thus, behavioral engagement in the passionate activity can be seen as flexible.

Conversely, obsessive passion, results from a controlled internalization of the activity that one loves into identity. Such an internalization process leads not only the activity representation to be part of the person's identity, but also to values and regulations associated with the activity, to be at best partially internalized in the self, and at worse to be internalized in the person's identity but completely outside the integrative self (Deci \& Ryan, 2000). A controlled internalization originates from intra and/or interpersonal pressure typically because certain contingencies are attached to the activity such as feelings of social acceptance or selfesteem, or because the sense of excitement derived from activity engagement is uncontrollable (Mageau, Carpentier, \& Vallerand, 2011). People with an obsessive passion can thus find themselves in the position of experiencing an uncontrollable urge to partake in the activity they view as important and enjoyable. They cannot help but to engage in 
the passionate activity. The passion must run its course as it controls the person. Consequently, they risk experiencing conflicts and other negative affective, cognitive, and behavioral consequences during and after activity engagement. For instance, returning to the example of the student who needs to prepare for the important oral presentation that still needs work, if the student has an obsessive passion for basketball, he might not be able to resist an invitation to play with his friends. During the game, he might feel upset with himself for playing basketball instead of preparing the presentation. He might therefore have difficulties focusing on the task at hand (playing basketball) and may not experience as much positive affect and flow as he could while playing.

In line with the above example, it is thus proposed that individuals with an obsessive passion come to display a rigid persistence toward the activity, as oftentimes they can't help but to engage in the passionate activity. This is so because ego-invested, rather than integrative, self-processes (Hodgins \& Knee, 2002) are at play with obsessive passion leading the person to eventually becoming dependent on the activity. While such persistence may lead to some benefits (e.g., improved performance at the activity), it may also come at a cost for the individual, potentially leading to less than optimal functioning within the confines of the passionate activity because of the lack of flexibility that it entails. Furthermore, such a rigid persistence may lead the person to experience conflict with other aspects of his or her life when engaging in the passionate activity (when one should be doing something else, for instance), as well as to frustration and rumination about the activity when from engaging in it. Thus, if the obsessively passionate basketball player manages to say no to his friends and the basketball scrimmage, he still may end up suffering because he may have difficulties concentrating on his studying because of ruminations about the lost opportunity to play basketball.

\section{Research on Passion}

Over the past few years, we have conducted a number of studies on passion. In fact well over 100 studies have now been conducted on passion, including several from laboratories other than our own. However, in the present paper, we mainly focus on our own research. These studies pertain to a variety of activities, settings, participants, and outcomes. Below, we briefly review the results of some of these studies that pertain to the concept of passion, emotions and flow, psychological well-being, physical health, interpersonal relationships, and performance.

\section{Initial Research}

There were two major purposes to the initial study (Vallerand et al., 2003, Study 1): to develop the Passion Scale and to test the validity of the passion definition. Thus, over 500 university students completed the Passion Scale with respect to an activity that they loved, that they valued, and in which they invested time and energy (i.e., the passion definition), as well as other scales allowing us to test predictions derived from the Passion Model. A large variety of passionate activities were reported ranging from physical activity and sports to watching movies and reading. Participants reported engaging in their passionate activity for an average of 8.5 hours per week and had been engaging in that activity for almost 6 years (see also Stenseng, 2008 for similar results). Thus, clearly passionate activities are meaningful to people and do not simply reflect a fleeting interest. Interestingly, $84 \%$ of our participants indicated that they had at least a moderate level of passion for a given activity in their lives (they scored at least 4 out of 7 on a question asking them if their favorite activity was a «passion» for them). It would thus appear that the prevalence of passion is rather high.

Results from the Vallerand et al. (2003, Study 1) study as well as from subsequent research have provided empirical support for several aspects of the passion conceptualization. First, empirical support has been obtained for the validity and reliability of the Passion Scale. Specifically, Vallerand et al. (2003, Study 1) randomly split their sample of over 500 participants in two subsamples. After conducting an exploratory factor analysis supporting the presence of two factors corresponding to the two types of passion with the first sample, they confirmed the bi-factorial structure with the second sample using confirmatory factor analysis. These findings on the factor validity of the Passion Scale has been replicated in a number of studies conducted both in a variety of activity and life domains (e.g., Carbonneau, Vallerand, Fernet, \& Guay, 2008; Castelda, Mattson, MacKillop, Anderson, \& Donovick, 2007; Lafrenière, Jowett, Vallerand, Donahue, \& Lorimer, 2008, Studies 1 and 2; Philippe, Vallerand, Adrianarisoa, \& Brunel, 2009, Studies 1 and 2; Rousseau \& Vallerand, 2008; Rousseau,Vallerand, Ratelle, Mageau, \& Provencher, 2002 ; Vallerand, Mageau et al., 2008, Studies 1 and 2; Vallerand, Ntoumanis et al., 2008; Vallerand, Rousseau, Grouzet, Dumais, \& Grenier, 2006). In addition, in a study with over 3,500 participants, Marsh and colleagues (2012) have shown that the scale is reliable and valid and is equivalent both in English and French, for both men and women, across various age groups, and for a 
number of different activities. Thus, the scale can be readily used for most if not all types of activities and populations.

The Passion Scale consists of 2 subscales of 6 items each assessing obsessive (e.g., "I almost have an obsessive feeling toward this activity") and harmonious passion (e.g., "This activity is in harmony with other activities in my life"). Furthermore, internal consistency analyses have shown that both subscales are reliable (typically .75 and above). In addition, test-retest correlations over periods ranging from four to six weeks revealed moderately high stability values (in the .80 s, Rousseau et al., 2002), thereby supporting the hypothesis that although the two subscales are relatively stable (and thus, that there seems to be a predominant form of passion for each individual), there is still room for some temporary fluctuations. Finally, the scale has been found to be free from social desirability (Rousseau et al., 2002).

A second series of critical findings yielded support for the construct validity of the two types of passion, harmonious and obsessive. These findings pertained to the results from partial correlations (controlling for the correlation between the two types of passion) which showed that both harmonious and obsessive passions are positively associated with the passion criteria and measures of the activity being perceived as a passion, thereby providing support for the definition of passion (e.g., see Vallerand, 2010; Vallerand et al., 2003, Study 1). In addition, although both types of passion have been found to relate to one's identity (e.g., Vallerand et al., 2003, Study 1; Vallerand, Noutmanis et al., 2008, Study 1), obsessive passion has been found to more strongly relate to measures of both identity and conflict with other life activities than harmonious passion (e.g., Marsh et al., 2012; Vallerand et al., 2003, Study 1; Vallerand, Noutmanis et al., 2008, Study 3). Thus, overall, these findings support the view that both harmonious and obsessive passion are indeed a "passion" as each one reflects the definition of the passion construct.

In sum, initial research provided support for the concept of harmonious and obsessive passion. We now turn to research that has explored some of the outcomes associated with the passion construct that have some important implications for positive psychology.

\section{Passion and Flow}

Flow (Csikszentmihalyi, 1978; Csikszentmihalyi, Rathunde, \& Whalen, 1993) refers to a desirable state that people experience when they feel completely immersed in the activity (e.g. "I have a feeling of total control"). Based on the Dualistic Model of Passion, it would be expected that harmonious passion facilitates adaptive cognitive processes such as flow, whereas obsessive passion should not, or at least less so. This is so because with harmonious passion, integrative self processes are at play leading the person to fully partake in the passion activity with an openness that is conducive to mindful attention, concentration, and flow. The situation is different when obsessive passion is at play because ego-invested processes are involved (Hodgins \& Knee, 2002), thereby leading individuals to adopt a defensive orientation that only permits a partial investment in the activity. Thus, less flow should be experienced in the process.

Research provides support for this hypothesis. For instance, in the Vallerand et al. (2003, Study 1), results revealed that harmonious passion facilitates the experience of flow, whereas obsessive passion does not. These results have been replicated in various fields such as the work domain (Forest et al., 2011; Lavigne, Forest, \& Crevier-Braud, 2012) and sports (Philippe, Vallerand, Andrianarisoa, \& Brunel, 2009, Study 1). Of additional interest are the findings of Lavigne et al. (2012, Study 2) obtained in the work domain. Using a cross-lagged panel design, these authors replicated the above findings. In addition, these authors also showed that passion predict changes in flow over time, while flow does not affect passion. These findings thus suggest that passion causes the experience of flow while flow does not affect passion.

\section{Passion and Affect}

Given that task valuation increases affect (Brown \& Weiner, 1984), being passionate for an activity should also increase affect. However, the type of affect should differ as a function of the type of predominant passion held by the person. Thus, with harmonious passion, people volitionally engage in the passionate activity with an openness and a mindfulness that allow them to fully partake in the activity, and thus to experience positive affective experiences (Hodgins \& Knee, 2002) during task engagement (e.g., positive affect). Furthermore, the lack of conflict with other life activities that harmonious passion entails should maximize the duration of the positive affect experienced during activity engagement and lead one to experience positive affect after task engagement. Finally, because task engagement is volitional, one is unlikely to experience negative affect when unable to engage in the passionate activity (such as feelings of dependence).

Conversely, with obsessive passion, one engages in the activity with a defensive, rather than an open, orientation preventing one from fully experiencing the positive emotions 
that should be derived from engaging in one's favorite activity. Moreover, because engagement is often out of one's control, and may be performed at ill-advised times, some conflict may thus be experienced with other life activities, thereby preventing one from fully enjoying participation in the passionate activity and leading one to experience negative affect following task engagement. (e.g., guilt, shame, anxiety). Finally, one is likely to experience high levels of negative affect when prevented from engaging in the passionate activity because engagement in the passionate activity out of obsessive passion is experienced as an uncontrollable desire to partake in the activity. Consequently, being prevented from engaging in the passionate activity should lead to some sense of suffering.

Results from a number of studies have supported these hypotheses in a number of studies. For instance, Vallerand et al. (2003, Study 1) asked college students who were passionate toward an activity to complete the Passion Scale and to report the positive and negative emotions they typically experience during and after task engagement, as well as when they are prevented from engaging in their passionate activity. Results from partial correlations (controlling for obsessive passion) revealed that harmonious passion was positively associated with positive emotions during activity engagement. In addition, harmonious passion was positively related to positive emotions and the absence of negative affect following task engagement, and the absence of negative emotions when prevented from engaging in the passionate activity. On the other hand, when controlling for harmonious passion, obsessive passion was positively associated with negative emotions (especially shame) and unrelated to positive emotions both during and following activity engagement. Furthermore, obsessive passion was strongly related to negative affect when one was prevented from engaging in the activity. These results have been replicated in a number of studies (see Vallerand, 2008, 2010), including studies dealing with how athletes (e.g., Vallerand et al., 2006, Studies 2 and 3) and referees (e.g., Philippe, Vallerand, Andrianarisoa, \& Brunel 2009, Study 1) typically feel when engaged in their sport.

If passion contributes to situational affective experiences during activity engagement, can it also influence one's general affect in life (i.e., outside the purview of the passionate activity)? Indeed, it could be hypothesized that because the passionate activity is highly valued, affect experienced as a function of engagement in the passionate activity should spill over in one's life in general. A 14-day diary study conducted by Mageau and Vallerand (2007) suggests that such is the case. Participants who had engaged in their passionate activity during the day experienced high levels of positive emotions at the end of the day but only if their harmonious passion was high. On the other hand, people with a predominant obsessive passion experienced a drop of positive emotions on days when they did not engage in the passionate activity.

The Mageau and Vallerand (2007) study only lasted for 14 days. Can passion influence affect over a longer period of time? In order to test this hypothesis, Vallerand et al. (2003, Study 2) followed collegiate football players over the course of an entire football season (over 4 months) and assessed passion and general positive and negative affect prior to and after the end of the season. Results revealed that harmonious passion predicted an increase in general positive affect, whereas obsessive passion predicted an increase in general negative affect, in one's life over the course of the entire football season. Furthermore, these findings were obtained while controlling for intrinsic and extrinsic motivation toward football. Thus, passion matters not only with respect to situational affect experienced within the purview of the passionate activity, but also as pertains to general affect in life.

Finally, a recent study also looked at the ability of passionate individuals to predict their future affective states (i.e., affective forecasting) following success and failure events within the purview of the passionate activity (Verner-Filion, Lafrenière, \& Vallerand, 2012). Because it is closely aligned with self-processes that allow the person to readily face events and experiences, it was predicted that harmonious passion would facilitate better affective forecasting than obsessive passion. Findings from the Verner-Fillion et al. (2012) research provided support for this hypothesis with soccer sports fans. Specifically, soccer fans' harmonious passion was positively associated with greater accuracy (or better affective forecasting) when predicting the emotional consequences following both a win and a defeat of their favorite team. In contrast, obsessive passion was unrelated to affective forecasting accuracy.

\section{Passion and Psychological Well-Being}

The Dualistic Model of Passion would predict that engaging in a meaningful and enjoyable activity that provides us with opportunities for self-improvement and actualization should facilitate one's psychological well-being to the extent that one's passion for the activity is harmonious in nature. Research provides support for this hypothesis. For instance, in a study with elderly individuals, Rousseau and Vallerand (2003) showed that harmonious passion positively 
predicted positive indices of psychological well-being (life satisfaction, meaning in life, and vitality) but negatively predicted negative indices (anxiety and depression). Conversely, obsessive passion positively predicted anxiety and depression, was negatively related to life satisfaction, and was unrelated to meaning in life and vitality. Research with young adults and teenagers using different measures of psychological well-being has yielded similar findings. Specifically, harmonious passion was positively related to life satisfaction and vitality (Vallerand et al., 2007, Studies 1 and 2; Vallerand et al., 2008, Study 2), while obsessive passion was either negatively related (Vallerand et al., 2007, Study 2) or unrelated (Vallerand et al., 2007, Study 1; Vallerand et al., 2008, Study 2) to these indices.

If passion affects psychological well-being, then what are the processes mediating such effects. We feel that at least two processes might be at play. A first deals with the repeated experience of situational (or state) positive affect during the course of engagement of the passionate activity. The work of Barbara Fredrickson (e.g., 2001; Fredrickson \& Joiner, 2002) reveals that positive emotions open the mind to various positive functions, including having access to adaptive cognitive and self repertoires that allow one to thrive and to adapt positively to various situations. Research on passion (e.g., Mageau et al., 2005; Vallerand et al., 2003, Study 1) has shown that harmonious passion positively contributes to the experience of positive affect during activity engagement. Because passionate individuals engage on average for about 8 hours per week in their passionate activity, this means that harmonious passion can lead people to experience 8 hours of cumulative positive affect per week on top of what may be experienced in other life domains. Such cumulative experience of positive affect may facilitate psychological well-being (Fredrickson, 2001).

A research by Rousseau and Vallerand (2008) provided support for this hypothesis with passion toward physical activity. At Time 1, participants completed the Passion Scale with respect to physical activity, as well as measures of psychological well-being. At Time 2, immediately following an exercise session, they completed situational measures of positive and negative affect. Finally, at Time 3 , they completed measures of psychological well-being again. Results from a path analysis revealed that harmonious passion positively predicted positive affect, which led to increases in psychological well-being from Time 1 to Time 3. On the other hand, obsessive passion was unrelated to positive affect but positively predicted negative affect. The latter did not predict psychological well-being. Obsessive passion also had a direct negative link to psychological well-being. These basic findings were replicated in another study (Rousseau \& Vallerand, 2008). Overall, these findings provide strong support for the role of situational positive affect experienced during task engagement as a mediator of the effect of harmonious passion on psychological well-being.

The above research suggests that harmonious passion positively contributes to psychological well-being through the repeated experience of situational positive affect. However, such research also showed that although obsessive passion is negatively related to psychological well-being, such a relationship is mediated by neither positive affect nor situational negative affect. So, what is the mediator of such a relationship? We posit that rigid persistence in activities with negative returns for the person represents the second process mediating the effects of (especially obsessive) passion on psychological well-being. Because the passionate activity is very dear to the heart of those who engage in it (after all it is part of their identity), people are likely to persist in them for a rather long period of time. However, as described previously, there would seem to be some differences in the type of persistence associated with the two types of passion. Specifically, with harmonious passion, the persistence is flexible while it is rigid with obsessive passion. Such rigid persistence can lead the person to persist in the passionate activity even though some permanent negative consequences are experienced, eventually leading to low levels of psychological well-being. Such should not be the case for harmonious passion.

Research of ours in the realm of gambling provides supports for this analysis. Indeed, research has shown that obsessive passion predicts pathological gambling while harmonious passion is unrelated to it (Ratelle, Vallerand, et al., 2004; Rousseau, Vallerand, et al., 2002). Furthermore, in a recent study on the prevalence of gambling problems (Philippe \& Vallerand, 2007), it has also been shown that obsessive passion predicts the occurrence of pathological gambling. Finally, in a last study (Vallerand et al., 2003, Study 4) on gambling, we tested whether rigid persistence toward the passionate activity is really at play in psychological problems. In this study, we compared the two types of passion of regular casino gamblers (who played at least once a week) with those of people with gambling problems so severe that they ended up asking the Montreal Casino to bar them from entry. Clearly, these individuals do have important gambling problems ( $93 \%$ of the self-exclusion sample displayed pathological gambling vs. $37 \%$ for the regular casino players). As such, the self-exclusion gamblers should have stopped gambling a long time ago. And yet, they did not. The results revealed that the self-exclusion 
gamblers reported significantly higher levels of obsessive passion than regular casino gamblers. No difference existed on harmonious passion. Furthermore, for the self-exclusion group, their obsessive passion was much higher than their harmonious passion. There were no differences between the two scales for the control group (the regular casino players).

In sum, preliminary evidence reveals that passion affects psychological well-being through at least two mediating processes. First, harmonious passion positively contributes to psychological well-being through its impact on situational positive affect. Second, obsessive passion may even detract from well-being. This negative effect on psychological wellbeing takes place through the impact of obsessive passion on rigid persistence in an ill-advised form of activity such as gambling.

\section{Passion and Physical Health}

Passion can affect one's physical health in a number of ways. A first deals with the impact that passion has on the level of energy experienced when engaging in the activity. In line with research on the role of passion in positive emotions, it is hypothesized that harmonious passion would be more positively related to high energy than obsessive passion. In a first study with competitive high school basketball players, Vallerand et al. (2006, Study 2) asked participants to complete the Passion Scale as well as the Vitality scale with respect to when they play in general (e.g., "I feel alive and full of energy when I play basketball"; Ryan \& Fredrick, 1997). Results of partial correlations revealed that harmonious passion was positively and significantly correlated with vitality. In contrast, obsessive passion was unrelated to it. Similar results have been obtained in other studies conducted with respect to passion for one's studies (Stoeber, Childs, Hayward, \& Feast, 2011) as well as for exercise with senior citizens (Rousseau \& Vallerand, 2008). Of additional interest, in the Stoeber et al. study, intrinsic and extrinsic motivation were not found to predict energy (vigor) while passion did.

A second health effect of passion refers to the boost in energy that may be experienced after activity engagement. Typically, we would hope for passion to leave us with higher levels of energy and vitality and lower levels of tension and emotional exhaustion than before activity engagement. If such were the case, this would represent an important contribution of passion to our health. Imagine if one could engage in one's passionate activity when tired or stressed out and experience a boost of energy and a reduction in stress after engaging in the activity! The passionate activity could serve as an energy booster. This would represent a valued health outcome as people could now use this increased energy to embark in other life activities with more zest. However, such an effect should take place only if the activity is fueled by harmonious passion. With obsessive passion, engagement in the activity may even leave the person with less energy and more stress and tension than before. Then, such a loss in energy can have drastic effects on health. Indeed, some authors have posited that our body has a finite quantity of energy. If we use up too large a quantity of our energy, this can lead to important health problems as people may not be able to use their energy to control their urges to engage in unhealthy behavior such as drinking, smoking, and eating unhealthy food (see Baumeister \& Tierney, 2011)

In a study on passion and gaming discussed previously, Przybylski et al., (2009) had video game players completed an online questionnaire that contained the Passion Scale as well as the Activation-Deactivation Adjective Checklist (Thayer, 1986). This measure contains scales assessing postplay energy (feeling active, energetic, vigorous, etc., after having played) and postplay tension (e.g., feeling jittery, fearful etc., after having played). As expected, results of correlations revealed that harmonious passion was positively related to postplay energy, but unrelated to postplay tension. In contrast, obsessive passion was positively related to both postplay energy and postplay tension (although the correlation with postplay energy was weaker than that involving harmonious passion).

Of interest is that other studies have looked at the role of passion in feeling empty and exhausted (the opposite to experiencing high energy) following their engagement in the activity. For instance, in a study with Swedish athletes in sports academy, Gustafsson et al. (2011) had athletes complete the emotional exhaustion subscale of the Athlete Burnout Questionnaire (Raedeke \& Smith, 2001) in addition to the Passion Scale. Results with the emotional exhaustion (e.g., "I feel overly tired from my participation in basketball") revealed that harmonious passion was negatively related to emotional exhaustion while obsessive passion was positively related to it. Other sports studies yielded inconsistent findings. For instance, in a study with basketball players, Lalande et al. (2013, Study 3) found that obsessive passion was positively (and significantly) correlated to emotional exhaustion while harmonious passion was unrelated to it. However, in another study with teenagers elite soccer players (Curran, Appleton, Hill, \& Hall, 2011), results revealed no significant correlations between either type of passion and emotional exhaustion. Finally, in the Stoeber et al. (2011) study reported above on passion for 
one's studies, harmonious passion was negatively related to exhaustion but no significant relationship was obtained for obsessive passion.

Although there are some inconsistencies, the results from the studies reviewed above lead to the following conclusions. First, harmonious passion provides high energy during activity engagement while obsessive passion may not or at least, will contribute less energy than harmonious passion. Second, after having engaged in an activity out of harmonious passion, one tends to experience more energy and overall less tension and emotional exhaustion than if one's engagement is fueled by obsessive passion. While obsessive passion may leave one with an increase in energy, such energy seems to be accompanied with tension and sometimes with exhaustion. Thus, when obsessive passion does lead to an increase in post-activity energy it seems to be of lesser quality than that triggered by harmonious passion. However, because the findings dealing with post-activity energy (and its opposite, emotional exhaustion) were not always perfectly replicated, future research is needed on this issue.

A third way through which Passion can affect one's physical health is by promoting exercise adherence. Research reveals that engaging in as little as 15 minutes of physical activity per day can decrease mortality by $14 \%$ or to add three years to your life (Wen et al., 2011). Based on what we have seen so far on passion, it follows that one of the safest ways to ensure that we engage in such healthy behavior (and derived the health benefits) would be to become passionate for a type of physical activity. Indeed, the Dualistic Model of Passion posits that when passionate about an activity, people will engage in it regularly, each time for a rather long period of time. Further such a regimens can be sustained over several years and sometimes a lifetime. And such engagement should be basically the same for both the harmonious and obsessive passions. Research provides support for these hypotheses. Specifically, using various indices of regular engagement in physical activity (e.g., exercise, yoga, sports) research reveals that typically both harmonious and obsessive passions positively predict engagement and persistence in such types of activities (Carbonneau, Vallerand, \& Massicotte, 2010; Halvari et al., 2009; Parastatidou et al., 2012; Stephan et al., 2009). Of interest is the fact that the relationship involving obsessive passion is slightly higher than that involving harmonious passion, possibly due to the rigid persistence that obsessive passion entails. The bottom line is that having a passion (harmonious or obsessive) for physical activity promotes sustained engagement in it thereby leading to important health benefits.
A fourth positive effect of passion is that it may protect one from experiencing nagging acute injuries such as ankle twists, pulled muscles, and the like. For instance, in one study with dancers (Rip, Fortin, and Vallerand (2006) asked modern-jazz dance student and professional dancers to complete a questionnaire. The questionnaire contained the Passion Scale for dancing and questions dealing with the number of days over the past 12 months where they could not dance because of acute injuries (defined as punctual injuries such as muscle pulls and twisted ankles that were not recurring injuries). Results from partial correlations revealed that both the harmonious and obsessive passions were negatively correlated with the number of days missed because of acute injuries. In other terms, the more one is passionate, the less one is severely injured. Thus, being passionate for some form of exercise such as dance serves to protect the person from acute injuries while dancing. It should be noted that being in top physical shape may also have its advantages outside the dance activity. For instance, being in great physical shape may help one walk steadily on icy sidewalks in winter without falling and risking an injury.

Passion may also lead to some negative effects. One such effect may take place by leading one to engage in risky behavior. Take cycling for instance. While cycling in the spring, summer, and fall can be a lot of fun and can promote one's health, cycling in winter can be highly hazardous (at least in the Province of Quebec). If our hypothesis on the rigid persistence of obsessive passion is correct, then obsessive passion should lead one to engage in risky behaviors such as winter cycling. On the other hand, if we are correct with respect to the flexible persistence of harmonious passion, then the latter should not lead to engage in such a behavior. In a recent study (Vallerand et al., 2003, Study 3) we tested these hypotheses. Cyclists completed the Passion Scale with respect to cycling in August. Six months later, they were contacted again to determine who was still cycling in the dead of winter (in February). Results showed that obsessive (but not harmonious) passion predicted cycling in winter. Thus, obsessive passion may potentially affect people's health by leading them to engage in certain risky activities while they should not (such as cycling in sub-zero temperature on icy roads).

A second type of negative health effect of obsessive passion is that it may lead one to rigidly persist in an activity when injured, thereby leading to chronic injuries. A recent study with dancers (Rip et al., 2006) has looked at this issue. Obsessive passion, as we have seen earlier, is associated with rigid persistence. Therefore, when injured, obsessive passion should lead people to continue dancing 
because they cannot stop as they are controlled by their passion for dancing. Such ill-advised persistence, however, may lead to chronic injuries. On the other hand, with harmonious passion, the person is in control of the activity. Thus, persistence can be seen as flexible. As such, when dancing out of harmonious passion, the dancer can decide to stop dancing when injured if there is a risk of developing a chronic injury. In the Rip et al. (2006) study discussed previously, participants also completed questions dealing with the number of weeks missed due to chronic injuries. Results from correlations revealed that obsessive passion was positively related to the number of weeks missed because of chronic injuries, while harmonious passion was unrelated to chronic injuries.

Additional research with yoga exercisers revealed that only those with a harmonious passion were able to derive positive psychological and health benefits from their regular engagement (Carbonneau, Vallerand, \& Massicotte, 2010). Because Yoga is perceived as one of the most beneficial form of physical activities, these results show that the quality of the outcome derived form an activity depends on the type of passion one has for an activity rather than the inherent qualities of the activity itself. Finally, a recent research with breast cancer survivors (Burke, Sabiston, \& Vallerand, 2012) showed that harmonious passion for an activity was associated with higher positive affect and lower cancer worry during the remission period. Such was not the case for obsessive passion. In addition, obsessive passion was positively linked to cancer worry that has been found to predict cancer relapse (see Burke et al., 2012).

In sum, the general picture derived from the research described above is that, overall, harmonious passion leads to a number of positive effects on one's physical health. On the other hand, obsessive passion leads to mitigated effects, sometimes positive (e.g., energy) and sometimes negative through rigid persistence toward activities (even for supposedly positive activities), engagement in risky behavior, and by promoting negative consequences for cancer survivors through cancer worry.

\section{Passion and Interpersonal Relationships}

Passion can also affect the quality of the relationships we develop and maintain. This can take place in at least three ways. First, because passion affects the way people engage in the passionate activity, it can also indirectly influence the quality of relationships that take place within the purview of the activity. The Dualistic Model of Passion posits that having a harmonious passion for a given activity should facilitate having positive relationships with others while engaging in the passionate activity. Further, such positive effects should be mediated by the experience of positive affect. This is so because positive affect facilitates smiling, positive sharing of the activity, connection, and openness toward others that are conducive to positive relationships (see Waugh \& Fredrickson, 2006). Because harmonious passion leads one to experience positive affect during engagement in the passionate activity, one would then predict that it should therefore indirectly lead to high quality relationships within the passionate activity. Conversely, because it is typically unrelated to positive affect and positively related to negative affect, obsessive passion should facilitate quality of relationships and may even negatively affect relationships. A result from a series of 4 studies conducted in a variety of settings, including the work domain, has provided support for these hypotheses (Philippe, Vallerand, et al., 2010). Further, in some studies, the quality of the relationships was assessed by both the passionate participants and the people interacting with whom the passionate participants engaged in the activity. The same findings were obtained. Finally, the same findings were also obtained as pertains to new and existing relationships. Thus, the same processes operate for the development and maintenance of relationships.

A second type of relationship effects deals with the impact that passion has on the quality of relationships that one has outside of the passionate activity. Results from the Vallerand et al. (2003, Study 1) provided preliminary evidence for this hypothesis by showing that obsessive (but not harmonious) passion for an activity was positively associated with experiencing conflict between activity engagement and other aspects of one's life. We believe that this basic hypothesis has important implications for the quality of interpersonal relationships that people may experience outside the realm of the passionate activity. For instance, in a study with English soccer fans (Vallerand et al., 2008, Study 3), it was found that having an obsessive passion for being a soccer fan predicted conflict between soccer and couple relationship. Conflict, in turn, negatively predicted satisfaction with the romantic relationship. Harmonious passion was unrelated to conflict. Similar findings were obtained in another study on passion for the Internet and dyadic functioning (Séguin-Lévesque, Laliberté, Pelletier, Blanchard, \& Vallerand, 2003).

Finally, a third and last area where passion can affect relationships pertains to the impact one's passion for the loved one can have on the quality of the intimate relationship. In line with past research on passion for activities, harmonious passion for the loved on should predict high 
quality of the relationship, while obsessive passion should be either negatively related or unrelated to the quality of the relationship. In two recent studies, Ratelle, Carbonneau, Vallerand, and Mageau (in press) examined how these two types of romantic passion relate to indices of romantic relationship quality, how one's own passions are associated with one's partner's passions and relationship quality, and how the two types of passion relate to relationship stability over time. Results from the Ratelle et al. (2004) research revealed that harmonious passion was more strongly associated with high relationship quality than obsessive passion. Those findings applied to both genders. Furthermore, results revealed that types of passion predicted relationship status over a 3-month period. Specifically, only harmonious passion positively predicted the continuity of the relationship, over and above the effects of gender and relationship quality. Conversely, obsessive passion negatively predicted relationship continuity, although marginally so. Future research on this issue would appear particularly exciting, especially as pertains to the identification of the behaviors and processes through which such passion effects take place on the quality of intimate relationships.

\section{Passion and Performance}

Research on expert performance reveals that high-level performers spend several years of considerable engagement in deliberate practice (or engagement in the activity with clear goals of improving on certain task components), in order to reach excellence in their chosen field of expertise (see Ericsson \& Charness, 1994; Starkes \& Ericsson, 2003). One may ask the question: What is the underlying motivational force that leads individuals to spend so much time in perfecting their skills in a given activity in order to achieve high proficiency? We believe that passion represents one answer to this question. Indeed, if one is to engage in the activity for long hours over several years and sometimes a lifetime, one must love the activity dearly and have the desire to pursue engagement especially when times are rough. Thus, the two types of passion (harmonious and obsessive) should lead to engagement in deliberate practice that, in turn, should lead to achieving high levels of performance. This model was tested in a study with athletes (Vallerand et al., 2008, Study 1) in which male and female basketball players completed scales assessing their passion as well as deliberate practice (based on Ericsson \& Charness, 1994). Coaches independently rated the athletes' performance. Results of a path analysis revealed that both types of passion led to engagement in deliberate practice, which, in turn, led to objective performance. These findings were replicated in a prospective design with dramatic arts performers (Vallerand et al., 2007, Study 1).

Also of interest is the finding that in the preceding study, harmonious passion toward dramatic arts was positively and significantly related to life satisfaction, while obsessive passion was unrelated to it. This is in line with research on passion and psychological well-being discussed previously. It thus appears that both types of passion positively contribute to deliberate practice and thus, indirectly, to performance at least in the short term. However, it might very well be that obsessive passion leads to some sense of "suffering" (or lower levels of psychological well-being than harmonious passion) in the process of pursuing high performance levels.

The results of the above studies revealed that both types of passion positively predict deliberate practice, and thus, indirectly predict performance. We conducted an additional study (Vallerand et al., 2008 Study 2) in order to examine the psychological processes through which passion contributes to deliberate practice, and thus indirectly contributes to performance. In line with Elliot (1997), we proposed that achievement goals should represent important mediators between passion and deliberate practice. Elliot and colleagues (Elliot \& Church, 1997; Elliot \& Harackiewicz, 1996) have distinguished between three types of achievement goals: mastery goals (which focus on the development of competence and task mastery), performance-approach goals (which focus on the attainment of personal competence relative to others), and performance-avoidance goals (which focus on avoiding incompetence relative to others). Passion has been found to relate to affective and cognitive investment in an activity (see Vallerand, 2010), thereby implying that the individual is committed to engaging in that activity in a competent manner. Harmonious passion, being a rather pure autonomous form of regulation is predicted to be positively related to mastery goals but not to performance goals of either type. On the other hand, obsessive passion, being a more pressured, internally controlling, form of regulation is likely to lead the individual to feel compelled to seek any and all forms of success at the activity, and may even evoke concerns about doing poorly. As such, obsessive passion should be positively related to mastery goals as well as performance-approach and performance-avoidance goals.

A study with water-polo and synchronized swimmers (including some who were part of the male and female junior national teams) was conducted over an entire season to test the above model (Vallerand et al., 2008, Study 2). At Time 1 , individuals completed the Passion Scale, the Achievement Goals Scale, and scales assessing psychological well-being. 
At Time 2, they completed the Deliberate Practice Scale. Finally, at Time 3, coaches assessed individuals' performance over the entire season. Results of a path analysis yielded support for the proposed model. Harmonious passion was found to lead to mastery goals that, in turn, led to deliberate practice that positively predicted objective performance. On the other hand, obsessive passion was positively related to all three goals. While performance-approach goals did not predict any variables in the model, performance-avoidance goals negatively predicted performance. Finally, as in the Vallerand et al. (2007, Study 1) study with the dramatic arts performers, harmonious passion was positively associated with psychological well-being while obsessive passion was unrelated to it. This basic model was replicated in another study involving students who had a passion toward studying psychology as their future profession and with objective exam scores in a psychology course as a measure of performance (Vallerand et al., 2007, Study 2). Similar results were also obtained with world-class musicians (Bonneville-Roussy, Lavigne, \& Vallerand, 2012). Overall, these results reveal that passion represents the fuel that triggers achievement goals that facilitate (mastery goals) engaging in deliberate practice repeatedly and relentlessly, so that over time they improve their skills in the activity. However, obsessive passion also fosters other types of goals, including performanceavoidance goals that may undermine performance.

In sum, the above research on passion and performance suggests the existence of two roads leading to performance attainment. The first road originates from harmonious passion and exclusively promotes a mastery focus that leads the person to engage in activities specifically aimed at skill improvement. Such deliberate practice eventually leads to high levels of performance. Of additional interest is that this harmonious engagement process also facilitates psychological well-being. The second road leading to performance attainment emanates from obsessive passion. Such a road is more complex than the first, as it involves the adoption of both adaptive (mastery goals) and maladaptive (performance-avoidance) achievement goals. This second road to performance would thus appear to be less than optimal for the individual. Indeed, in addition to leading to mixed performance through the adoption of mastery and performance-avoidance goals, it does not facilitate psychological well-being. Thus, contrary to what may be typically believed, one can be a high-level performer and lead a relatively balanced, happy, life at the same time, to the extent that harmonious passion underlies one's engagement in the field of excellence.

\section{Conclusion}

The purpose of the present paper was to present the Dualistic Model of Passion (e.g., Vallerand et al., 2003; Vallerand, 2010) and show the relevance of passion for the field of positive psychology. This model defines passion as a strong inclination toward a self-defining activity that one loves, finds important, and devotes significant amount of time and energy. Furthermore, the model proposes two types of passion that depend on how the activity representation has been internalized in one's identity, namely harmonious and obsessive passion. Harmonious passion entails control of the activity and a harmonious coexistence of the passionate activity with other dimensions of the self. Conversely, obsessive passion entails the relative lack of control over the passionate activity, and conflict with other activities in one's life. The Dualistic Model of Passion has received strong support, as the various studies described in the present paper show. Furthermore, the results of these studies reveal that harmonious passion promotes more adaptive outcomes than obsessive passion on a number of outcomes deemed highly important for the field of positive psychology, such as positive emotions and flow, psychological well-being, physical health, interpersonal relationships, and performance.

Positive psychology has asked the question "How people's lives can be most worth living?" (Seligman \& Csikscentmihalyi, 2000). We propose that one answer to that question is by having a harmonious passion toward a meaningful activity. Having such a passion allows one to experience a number of positive outcomes and to lead a fulfilling life worth living for. The concept of passion would thus appear to be of great relevance for positive psychology.

\section{References}

Aron, A., Aron, E. N., \& Smollan, D. (1992). Inclusion of other in the self scale and the structure of interpersonal closeness. Journal of Personality and Social Psychology, 63, 596-612.

Baum, J. R., \& Locke, E.A. (2004). The relationship of entrepreneurial traits, skill, and motivation to subsequent venture growth. Journal of Applied Psychology, 89, 587-598.

Baumeister, R. F., \& Tierney, J. (2011). Willpower: Rediscovering the greatest human strength. New York: The Penguin Press.

Bonneville-Roussy, A., Lavigne, G. L., \& Vallerand, R. J. (2011). When passion leads to excellence: the case of musicians. Psychology of Music, 39, 123-138.

Brown, J., \& Weiner, B. (1984). Affective consequences of ability and effort ascriptions: Empirical controversies, resolutions, and quandaries. Journal of Educational Psychology, 76, 146-158.

Brown, K. W., \& Ryan, R. M. (2003). The benefits of being present: Mindfulness and its role in psychological well-being. Journal of Personality and Social Psychology, 84, 822-848. 
Burke, S. M., Sabiston, C. M., \& Vallerand, R. J. (2012). Passion in breast cancer survivors: Examining links to emotional well-being. Journal of Health Psychology, 17, 1161-1175.

Carbonneau, N., Vallerand, R. J., Fernet, C., \& Guay, F. (2008). The role of passion for teaching in intrapersonal and interpersonal outcomes. Journal of Educational Psychology, 100, 977-987.

Carbonneau, N., Vallerand, R. J., \& Massicotte, S. (2010). Is the practice of yoga associated with positive outcomes? The role of passion. The Journal of Positive Psychology, 5, 452-465.

Castelda, B. A., Mattson, R. E., MacKillop, J., Anderson, E. J., \& Donovick, P.J. (2007). Psychometric validation of the Gambling Passion Scale (GPS) in an English-speaking university sample. International Gambling Studies, 7, 173-182.

Curran, T., Appleton, P. R., Hill, A. P., \& Hall, H. (2011). Passion and burnout in elite junior soccer players: The mediating role of self-determined motivation. Psychology of Sport and Exercise, 12, 655-661.

Csikszentmihalyi, M. (1978). Intrinsic rewards and emergent motivation. In M.R. Lepper \& D. Greene (Eds.), The hidden costs of reward (pp. 205-216). Hillsdale, NJ: Erlbaum.

Csikszentmihalyi, M., Rathunde, K., \& Whalen, S. (1993). Talented teenagers: The roots of success and failure. New York: Cambridge.

Deci, E. L., Egharri, H., Patrick, B. C., \& Leone, D. R. (1994). Facilitating internalization: The self-determination perspective. Journal of Personality, 62, 119-142.

Deci, E.L., \& Ryan, R. M. (2000). The "what" and "why" of goal pursuits: Human needs and the self-determination of behavior. Psychological Inquiry, 11, 227-268.

Descartes, R. (1649/1972). Les passions de l'âme. In E.S. Haldane \& G. Ross (Trans.) The philosophical works of Descartes. Cambridge, MA : Cambridge University Press.

Elliot, A.J. (1997). Integrating "classic" and "contemporary" approaches to achievement motivation: A hierarchical model of approach and avoidance achievement motivation. In P. Pintrinch \& M. Maehr (Eds.), Advances in motivation and achievement (vol. 10, pp. 143-179). Greenwich, CT: JAI Press.

Elliot, A. J., \& Church, M. A. (1997). A hierarchical model of approach and avoidance achievement motivation. Journal of Personality and Social Psychology, 72, 218-232.

Elliot, A. J., \& Harackiewicz, J. M. (1996). Approach and avoidance achievement goals and intrinsic motivation: A mediational analysis. Journal of Personality and Social Psychology, 70, 968-980.

Ericsson, K. A., \& Charness, N. (1994). Expert performance: Its structure and acquisition. American Psychologist, 49, 725-747.

Forest, J., Mageau, G. A., Sarrazin, C., \& Morin, E. M. (2011). "Work is my passion": The different affective, behavioral, and cognitive consequences of harmonious and obsessive passion toward work. Canadian Journal of Administrative Sciences, 28, 27-40.

Fredrickson, B. L. (2001). The role of positive emotions in positive psychology: the Broaden-and Build theory of positive emotions. American Psychologist, 56, 218-226.

Fredrickson, B. L., \& Joiner, T. (2002). Positive emotions trigger upward spirals toward emotional well-being. Psychological Science, 13, 172-175.

Frijda, N. H., Mesquita, B., Sonnemans, J., \& Van Goozen, S. (1991). The duration of affective phenomena or emotions, sentiments and passions. In K. T. Strongman (Ed), International review of studies on emotion (pp. 187-225). New York: Wiley.

Gustafsson, H., Hassmén, P., \& Hassmén, N. (2011). Are athletes burning with of passion? European Journal of Sport Sciences, 11, 387-395.

Halvari, H., Ulstad, S. O., Bagoien,T. E., Skjesol, K. (2009). Autonomy support and its link to physical activity and competitive performance: Mediations through motivation, competence, action orientation and harmonious passion, and the moderator role of autonomy support by perceived competence. Scandinavian Journal of Educational Research, $53,533-555$.

Hatfield, E., \& Walster, G. W. (1978). A new look at love. Reading, MA: Addison-Wesley.
Hodgins, H. S., \& Knee, R. (2002). The integrating self and conscious experience. In Deci, E. L., \& Ryan, R. M. (Eds.). (2002). Handbook on self-determination research: Theoretical and applied issues (pp. 87-100). Rochester, NY: University of Rochester Press.

Lafrenière, M-A., Jowett, S., Vallerand, R.J., Donahue, E. G., \& Lorimer, R. (2008). Passion in sport: On the quality of the coach-player relationship. Journal of Sport and Exercise Psychology, 30, 541-560.

Lalande, D. R., Vallerand, R.J., Lafrenière, M-A. K., Forest, J., \& Paquet, Y. (2013). On the Determinants of Harmonious and Obsessive Passions: The Role of Need Satisfaction Inside and Outside the Activity. Unpublished manuscript, Université du Québec à Montréal.

Lavigne, G., Forest, J., Crevier-Braud, L. (2012). Passion at work and burnout: A two-study test of the mediating role of flow experiences. European Journal of Work and Organizational Psychology, 21,518-546.

Mageau, G. A., Carpentier, J., \& Vallerand, R. J. (2011). The role of selfesteem contingencies the distinction between obsessive and harmonious passion. European Journal of Social Psychology, 41, 720-729.

Mageau, G., \& Vallerand, R. J. (2007). The moderating effect of passion on the relation between activity engagement and positive affect. Motivation and Emotion, 31, 312-321.

Mageau, G. A., Vallerand, R. J., Rousseau, F. L, Ratelle, C. F., \& Provencher, P. J. (2005). Passion and gambling: Investigating the divergent affective and cognitive consequences of gambling. Journal of Applied Social Psychology, 35, 100-118.

Marsh, H. W., Vallerand, R. J., Lafreniere, M. A. K., Parker, P., Morin, A. J. S., Carbonneau, N., . . Paquet, Y. (2012). Passion: Does one scale fit all. construct validity of two-factor passion scale and psychometric invariance over different activities and languages. Manuscritp submitted for publication.

Parastatidou, I. S., Doganis, G., Theodorakis, Y., \& Vlachopoulos, S. P. (2012). Exercising with passion : Initial validation of the Passion Scale in Exercise. Measurement in Physical Education and Exercise Science, 16, 119-134.

Peterson, C. P. (2006). A primer of positive psychology. New York: Oxford University Press.

Philippe, F. L., Vallerand, R. J., Andrianarisoa, J., \& Brunel, P. (2009). Passion in referees: Examining their affective and cognitive experiences in sport situations. Journal of Sport and Exercise Psychology, 31, 1-21.

Philippe, F. L., \& Vallerand, R. J. (2007). Prevalence rates of gambling problems in Montreal, Canada: A look at old adults and the role of passion. Journal of Gambling Studies, 23, 275-283.

Philippe, F. L., Vallerand, R. J., Houlfort, N., Lavigne, G. L., \& Donahue, E. G. (2010). Passion for an activity and quality of interpersonal relationships: The mediating role of emotions. Journal of Personality and Social Psychology, 98, 917-932.

Philippe, F. L., Vallerand, R. J., \& Lavigne, G. L. (2009). Passion does make a difference in people's lives: A look at well-being in passionate and non-passionate individuals. Applied Psychology: Health and WellBeing, 1, 3-22.

Przybylski, A. K.,. Weinstein, N., Ryan, R. M., \& Rigby, S. (2009). Having versus wanting to play: Background and consequences of harmonious versus obsessive engagement in video games. CyberPsychology \& Behavior, 12, 485-492.

Raedeke, T. D., \& Smith, A. L. (2001). Development and preliminary validation of an athlete burnout measure. Journal of Sport \& Exercise Psychology, 26, 525-541.

Ratelle, C. F., Carbonneau, N., Vallerand, R. J., \& Mageau, G. A. (in press). Passion in the romantic sphere: A look at relational outcomes. Motivation and Emotion, 1-15.

Ratelle, C., Vallerand, R. J., Mageau, G. A., Rousseau, F. L., \& Provencher, P. (2004). When passion leads to problematic outcomes: A look at gambling. Journal of Gambling Studies, 20, 105-119.

Rip, B., Fortin, S., \& Vallerand, R. J. (2006). The relationship between passion and injury in dance students. Journal of Dance Medicine \& Science, 10, 14-20. 
Robert J. Vallerand and Jérémie Verner-Fillion, Laboratoire de Recherche sur le Comportement Social, Université du Québec, Montréal, Québec, Canada. This research program was supported by grants from the Fonds Québécois pour la Recherche sur la Société et la Culture (FQRSC) and the Social Sciences Humanities Research Council of Canada (SSHRC). Rony, J. A. (1990). Les passions (The passions). Paris: Presses universitaires de France.

Rousseau, F.L., \& Vallerand, R. J. (2003). Le rôle de la passion dans le bien-être subjectif des aînés [The role of passion in the subjective wellbeing of the elderly]. Revue Québécoise de psychologie, 24, 197-211.

Rousseau, F. L., \& Vallerand, R. J. (2008). An examination of the relationship between passion and subjective well-being in older adults. International Journal of Aging \& Human Development, 66, 195-211.

Rousseau, F. L., Vallerand, R. J., Ratelle, C. F., Mageau, G. A., \& Provencher, P. J. (2002). Passion and gambling: On the validation of the Gambling Passion Scale (GPS). Journal of Gambling Studies, 18, 45-66.

Ryan, R. M., \& Deci, E. L. (2003). On assimilating identities of the self: A Self-Determination Theory perspective on internalization and integrity within cultures. In M.R. Leary \& J. P. Tangney (Eds.), Handbook of self and identity (pp. 253-272). New York: Guilford.

Ryan, R. M., \& Frederick, C. (1997). On energy, personality, and health: Subjective vitality as a dynamic reflection of well-being. Journal of Personality, 65, 529-565.

Séguin-Lévesque, C., Laliberté, M.-L., Pelletier, L. G., Blanchard, C., \& Vallerand, R. J. (2003). Harmonious and obsessive passion for the internet: Their associations with the couple's relationships. Journal of Applied Social Psychology, 33, 197-221.

Seligman, M. E. P., \& Csikscentmihalyi, M. (2000). Positive psychology: An introduction. American Psychologist, 55, 5-14.

Sheldon, K. M. (2002). The Self-Concordance Model of healthy goalstriving: When personal goals correctly represent the person. In E. L. Deci \& R. M. Ryan (Eds.), Handbook of self-determination research (pp. 65-86). Rochester, NY: The University of Rochester Press.

Starkes, J. L., \& Ericsson, K. A. (2003). Expert performance in sports: Advances in research on sport expertise. Champaign, IL: Human Kinetics.

Stenseng, F. (2008). The two faces of leisure activity engagement: Harmonious and obsessive passion in relation to intrapersonal conflict and life domain outcomes. Leisure Sciences, 30, 465-481.

Stephan, Y., Deroche, T., Brewer, B.W., Caudroit, J., \& Le Scanff, C. (2009). Predictors of perceived susceptibility to sport-related injury among competitive runners: The role of previous experience, neuroticsm, and passion for running. Applied Psychology: An International Review, 58, 672-687.

Stoeber, J., Harvey, M., Ward, J.A., Childs, J.H. (2011). Passion, craving, and affect in online gaming:Predicting how gamers feel when playing and when prevented from playing. Personality and Individual Differences, 51, 991-995.

Sternberg, R .J. (1986). A triangular theory of love. Psychological Review, 93, 119-153.
Thayer, R. E. (1986). Activation-Deactivation Adjective Check List (AD ACL).: Current overview and structural analysis. Psychological Reports, 56, 607-614.

Vallerand, R. J. (1997). Toward a hierarchical model of intrinsic and extrinsic motivation. Advances in Experimental and Social Psychology, 29, 271-360.

Vallerand, R. J. (2001). A hierarchical model of intrinsic and extrinsic motivation in sport and exercise. In G. Roberts (Ed.), Advances in motivation in sport and exercise (pp. 263-319). Champaign, IL: Human Kinetics.

Vallerand, R. J. (2007). A Hierarchical Model of Intrinsic and Extrinsic Motivation for sport and physical activity. In M. S. D. Hagger \& N. L. D. Chatzisarantis (Eds.), Self-determination theory in exercise and sport ( pp. 255-279). Champaign, IL: Human Kinetics.

Vallerand. R. J. (2008). On the psychology of passion: In search of what makes people's lives most worth living. Canadian Psychology, 49, 1-13.

Vallerand, R. J. (2010). On passion for life activities: The Dualistic Model of Passion. In M. P. Zanna (Ed.), Advances in Experimental Social Psychology (pp. 97-193). New York, NY: Academic Press.

Vallerand, R. J., Blanchard, C. M., Mageau, G. A., Koestner, R., Ratelle, C. F., . . . Léonard, M. (2003). Les passions de l'âme: On obsessive and harmonious passion. Journal of Personality and Social Psychology, $85,756-767$.

Vallerand, R. J., Fortier, M. S., Guay, F. (1997). Self-determination and persistence in a real-life setting: Toward a motivational model of high school dropout. Journal of Personnality and Social Psychology, 72, 1161-1176.

Vallerand, R. J., \& Houlfort, N. (2003). Passion at work: Toward a new conceptualization. In S. W. Gilliland, D. D. Steiner, \& D. P. Skarlicki (Eds.), Emerging perspectives on values in organizations (pp. 175-204). Greenwich, CT: Information Age Publishing.

Vallerand, R. J., Mageau, G. A., Elliot, A. J., Dumais, A., Demers, M. A., \& Rousseau, F. (2008). Passion and performance attainment in sport. Psychology of Sport and Exercise, 9, 373-392.

Vallerand, R. J., Ntoumanis, N., Philippe, F. L., Lavigne, G. L., Carbonneau, N., Bonneville, A., . . Maliha, G. (2008). On passion and sports fans: A look at football. Journal of Sports Sciences, 26, 1279-1293.

Vallerand, R. J., Rousseau, F. L., Grouzet, F. M. E., Dumais, A., \& Grenier, S. (2006). Passion in sport: A look at determinants and affective experiences. Journal of Sport \& Exercise Psychology, 28, 454-478.

Vallerand, R. J., Salvy, S. J., Mageau, G. A., Elliot, A. J., Denis, P. L., Grouzet, F. M. E., \& Blanchard, C. (2007). On the role of passion in performance. Journal of Personality, 75, 505-533.

Verner-Filion, J., Lafreniere, M. A. K., \& Vallerand, R. J. (2012). On the accuracy of affective forecasting: The moderating role of passion. Personality and Individual Differences, 52, 849-854.

Waugh, C. E., \& Fredrickson, B. L. (2006). Nice to know you: Positive emotions, self-other overlap, and complex understanding in the formation of new relationships. Journal of Positive Psychology, 1, 93-106.

Authors' Note. This research program was supported by grants from the Fonds Québécois pour la Recherche sur la Société et la Culture (FQRSC) and the Social Sciences Humanities Research Council of Canada (SSHRC). 